\title{
Assessment of Mother-Child (0 - 36 Months) Interaction, and Its Association with Socio-Emotional Development in Rural Area of Wardha District
}

\author{
Sumit Kishore ${ }^{1}$, Syed Zahiruddin Quazi², Priyanka Sumit Kishore³ ${ }^{3}$ Vikram Singh ${ }^{4}$, Rutuj Waghmare ${ }^{5}$ \\ 1, 2, 3, 4,5 Department of Community Medicine, Datta Meghe Institute \\ of Medical Sciences, Sawangi (M), Wardha, Maharashtra, India.
}

\section{ABSTRACT}

\section{BACKGROUND}

Infancy is a significant period in a human being's development. ${ }^{1}$ Adverse parenting practices can have negative impacts in the context of complete dependence and vulnerability of a child. Physical and psychological development of the child is also influenced by the relationship between the mother and the child. The purpose of the study was to assess the interaction and its association with socio-emotional development between mother and child in rural areas.

\section{METHODS}

A cross-sectional study was conducted in a rural area of Wardha district among 160 mother-child participants using Observation of Mother-Child Interaction (OMCI) and Profile of Socio-Emotional Development (PSED) tools for accessing mother-child interaction and socio emotional development of child. The sampling was done by complete enumeration sampling method. Written inform consent was taken from participants. Descriptive analysis was carried out in order to evaluate the measures of the collected result.

\section{RESULTS}

It is evident from this study that there is no statistically significant finding in motherchild interaction with socio emotional development i.e., P-value 0.081, and mother score having mean (SD) i.e., 22.99 ( \pm 5.38), child score having mean (SD) i.e., 13.19 ( \pm $3.84)$, total mother-child score having mean (SD) i.e., $18.03( \pm 6.70)$ and total PSED score having mean (SD) i.e., $15.63( \pm 6.15)$.

\section{CONCLUSIONS}

This study concludes that large responsive care ratings were related to enhance socio-emotional growth and responsive care with higher levels of maternal education as well as socioeconomic status. It can be further stated that inclusion of responsive care in child health interventions could have a valuable impact on child socioemotional development.

\section{KEY WORDS}

Mother-Child Interaction, OMCI, PSED, Socio Emotional Development

\author{
Corresponding Author: \\ Dr. Sumit Kishore, \\ Department of Community Medicine, \\ Datta Meghe Institute of Medical \\ Sciences, Sawangi (M), \\ Wardha, Maharashtra, India. \\ E-mail: sumitshrivas23@gmail.com
}

DOI: $10.14260 / j e m d s / 2021 / 281$

How to Cite This Article:

Kishore S, Quazi SZ, Kishore PS, et al. Assessment of mother-child (0 - 36 month) interaction and its association with socioemotional development in rural area of Wardha district. J Evolution Med Dent Sci 2021;10(18):1334-1337, 10.14260/jemds/2021/281

DOI:

Submission 27 -02-2020,

Peer Review 26-02-2021

Acceptance 06-03-2021,

Published 03-05-2021.

Copyright (C) 2021 Sumit Kishore et al. This is an open access article distributed under Creative Commons Attribution License [Attribution 4.0 International (CC BY 4.0)] 


\section{BACKGROUND}

Infancy is a significant period in a human being's development. ${ }^{1}$ Adverse parenting practices can have very negative impacts in the context of complete dependence and vulnerability of a child. The attachment to the mother and child as the main caretaker is a significant milestone in socioemotional growth by the end of a child's first year of life. In addition, the quality of attachment is regarded as an excellent index of communication between child and mother. ${ }^{1}$

Children's ability to understand the emotions of others, get along with other children, build a relationship with others, and the ability to regulate their own feelings and actions are all part of the socio-emotional growth of the child.2,3

Socio-emotional problems of children have a negative impact on their functioning, their milestone development and school readiness. ${ }^{4}$ All children and adolescence pursue a parallel pattern of growth so that each child advances from one milestone to the next. Each child develops at a different rate, however, and their growth may not advance uniformly in all areas. $^{5}$

Physical and psychological development of the child is also influenced by the relationship between the parent and the child. Parents provide their children with the experiences through their care and support they need to achieve their developmental milestones. ${ }^{6}$ Their primary interactive partners are the parents before children reach school age. It is easy to believe that mothers, who become the primary caregiver and a significant part of young children's social partner, have a tremendous impact on the development of their children. ${ }^{7}$

The socio emotional development of child is also equally important like how cognitive and physical development is. To develop socio emotional skills in child, it's the parents, caregiver and the teacher's responsibility to teach and foster these abilities as the child is not born with socio emotional skills.

By learning socio emotional skills, child enables to establish quality relationship with others, learn different things and get to know who they are in the world, learns to communicate, connect with others, how to settle disputes, create trust and achieve goals. Creating a solid socialemotional base as a child can help the child succeed and find happiness in life.

According to NCCP statistics, social-emotional problems that adversely affects the functioning, growth, and school readiness in young children between birth and five years of age was between 9.5 and 14.2 percent.

Around 9 percent of children receiving specialty mental health services are younger than 6 years of age in the United State. Four boys have a higher prevalence of behavioural problems than girls. ${ }^{8}$

The early years of childhood is not just the time for first steps or first words to be said. They are also when children build expectations about their world and the people in it through their relationships with others and develop their first, feeling good about themselves and what they can do, social skills to get along with others in life, such as recognizing, expressing, and managing a wide range of emotions. ${ }^{9}$

The purpose of the study was to assess the interaction and its association with socio-emotional development between mother and child in rural areas.

\section{METHODS}

Community-based descriptive cross-sectional study was conducted in a rural area of Wardha district, duration of the study was from July 2019 to February 2020 under the Seloo block of Wardha, 2 primary healthcare centres (PHC) namely Zadshi and Salaikala which were randomly selected, in which 1 PHC Salaikala was selected by complete enumeration of sampling method, with the total sample size being 160 . Interview technique was used to collect data by using a prestructured, questionnaire. The electronic tablet was used for data collection. "ODK collects" (Open Data Kit) application was used. The data was collected from sample households of the selected villages. The preceded, structured data collection tools which were used for data collection are as follows: Profile of socio-emotional development (PSED) was used in measuring the development of the child ( 0 to 3 years) towards independence, emotional regulation, and emotional control. Through this, we were looking at behaviour problems as an indicator of social and emotional maturity and Observation of mother-child interaction tool (OMCI). An assessment method for assessing contact between mother and child built to evaluate sensitive parenting skills was done by engaging 50 minutes between mother and child around an occurrence in a picture book. The mother was told to play with her child in the book as she usually would while a professional data collector examines and rates the behaviour. This was done at different ages of the child: $12,24,48$ months. ${ }^{10}$

\section{Statistical Analysis}

The data was analysed by using statistical package for the social sciences (SPSS) \& STATA statistical software and P < 0.05 is considered as the level of significance. Descriptive statistics and unpaired test were used to analyse the association of mother-child interaction and socio emotional development based on sociodemographic characteristics used in the present study.

\section{RESULTS}

The demographic characteristics of patients are shown in Table 1a. Study participant according to age, maximum number of study participants were in the age group $>12$ month $-<24$ months i.e., 127 (79.37\%) with mean $( \pm$ SD) $20.85( \pm 6.35)$ and median 20 . Table $1 \mathrm{~b}$ shows gender wise distribution of children, majority of children were female i.e., $87(54.37 \%)$ and males were 73 (45.62\%). Table 1c shows education wise distribution of mother, majority of mothers were educated up to secondary class i.e., 73 (10.62\%), followed by higher education i.e., 33 (3.12 \%). It also depicted that no mother was illiterate. Table $1 \mathrm{~d}$ shows distribution of study participants according to BG Prasad socio-economic scale which was used to measure the socioeconomic status and it revealed that $54(33.75 \%)$ were in class-2, followed by 39 $(24.37 \%)$ were in class-1, $38(23.75 \%)$ participants were in class-3, $29(18.12 \%)$ were in class- 4 .

Table 2 shows responses of mother child interaction for OMCI tool score; total 160 study participants were eligible for OMCI tool, the mother score having mean (SD) i.e., $22.99( \pm$ 
5.38) with minimum obtained score was 13 and maximum score was 36

\begin{tabular}{|c|c|c|}
\hline 1 (a) Children Age & $\begin{array}{l}\text { Study Participants } \\
\qquad \mathrm{N}=160\end{array}$ & Percentage (\%) \\
\hline$<12$ months & 3 & $1.87 \%$ \\
\hline$<12$ months $-<24$ month & 127 & $79.37 \%$ \\
\hline 25 - 36 months & 30 & $18.75 \%$ \\
\hline \multicolumn{3}{|l|}{1 (b) Children gender } \\
\hline Male & 73 & $45.62 \%$ \\
\hline Female & 87 & $54.37 \%$ \\
\hline \multicolumn{3}{|l|}{1 (c) Maternal education } \\
\hline Illiterate & - & - \\
\hline Primary (1 to 5 ) & 31 & $2.5 \%$ \\
\hline Secondary ( 6 to 10 ) & 73 & $10.62 \%$ \\
\hline Higher (11 \& 12) & 33 & $3.12 \%$ \\
\hline Graduate and above & 23 & $3.12 \%$ \\
\hline \multicolumn{3}{|l|}{$\begin{array}{l}1 \text { d) Socio economic status (BG } \\
\text { prasad socio-economic scale) }\end{array}$} \\
\hline Class-1 & 39 & $24.37 \%$ \\
\hline Class-2 & 54 & $33.75 \%$ \\
\hline Class-3 & 38 & $23.75 \%$ \\
\hline Class- 4 & 29 & $18.12 \%$ \\
\hline \multicolumn{3}{|c|}{$\begin{array}{l}\text { Table 1. Distribution of Study Participants According to } \\
\text { Socio-Demographic Characteristics. }(N=160) \text {. }\end{array}$} \\
\hline
\end{tabular}

\begin{tabular}{|ccccc|}
\hline 1 (a) OMCI & $\begin{array}{c}\text { Mean Score of } \\
\text { Respondents N - 160 }\end{array}$ & $\mathbf{\pm}$ SD & Min & Max \\
\hline Mother score & 22.99 & 5.38 & 13 & 36 \\
Positive affect & 2.30 & 0.62 & 1 & 3 \\
Negative affect & 2.48 & 0.78 & 0 & 3 \\
Positive touch & 2.10 & 0.72 & 0 & 3 \\
Negative touch & 2.71 & 0.58 & 0 & 3 \\
Positive verbal statements & 1.89 & 0.67 & 0 & 3 \\
Negative verbal statements & 2.62 & 0.61 & 0 & 3 \\
\hline Sensitivity & 1.58 & 0.78 & 0 & 3 \\
Scaffolding & 1.52 & 0.78 & 0 & 3 \\
Language stimulation & 4.06 & 2.54 & 0 & 9 \\
Focus & 1.67 & 0.74 & 0 & 3 \\
Child score & 13.19 & 3.84 & 1 & 21 \\
Positive affect & 4.21 & 1.50 & 1 & 6 \\
Negative affect & 2.32 & 0.91 & 0 & 3 \\
Remains focused & 3.05 & 1.28 & 0 & 6 \\
Communication & 1.42 & 0.93 & 0 & 3 \\
Mutual enjoyment & 2.16 & 0.77 & 0 & 3 \\
Mother + child score & 18.03 & 6.70 & 1 & 36 \\
\hline Table 2. Distribution of Study Participant on Basis of & \\
Responses of Mother Child Interaction for OMCI Tool Score \\
\hline \multicolumn{4}{|l}{} \\
\hline
\end{tabular}

\begin{tabular}{|ccccc|}
\hline $\begin{array}{c}\text { Socio-Emotional } \\
\text { Development Domain PSED }\end{array}$ & $\begin{array}{c}\text { Mean Score of } \\
\text { Respondents }\end{array}$ & $\mathbf{\pm S D}$ & Min & Max \\
1. Social competence & 5.84 & 3.23 & 0 & 15 \\
2. Emotional competence & 3.16 & 1.77 & 0 & 8 \\
3. Self-regulation & 7.81 & 3.44 & 1 & 15 \\
4. Executive functioning & 1.51 & 1.04 & 0 & 4 \\
Total PSED score & $\mathbf{1 5 . 6 3}$ & $\mathbf{6 . 1 5}$ & $\mathbf{3}$ & $\mathbf{3 1}$ \\
\hline Table 3. Distribution of Study Participant on Basis of Profile of \\
Socio-Emotional Development (PSED) Tool Score: ( $\mathbf{N}=\mathbf{1 6 0}$ ) \\
\hline
\end{tabular}

\begin{tabular}{|ccccc|}
\hline $\begin{array}{c}\text { Socio-Emotional } \\
\text { Development Domain }\end{array}$ & $\begin{array}{c}\text { Coef. } \\
(\mathbf{9 5} \% \mathbf{C I})\end{array}$ & Std Err & t-Test & P-Value \\
Social competence & $\begin{array}{c}-0.08 \\
(-0.52-0.35)\end{array}$ & 0.22 & -0.38 & 0.706 \\
\hline Emotional competence & $\begin{array}{c}-0.09 \\
(-0.89-0.70)\end{array}$ & 0.40 & -0.24 & 0.808 \\
\hline Self-regulation & $\begin{array}{c}-0.07 \\
(-0.47-0.32)\end{array}$ & 0.20 & -0.38 & 0.705 \\
\hline Executive functioning & $\begin{array}{c}-0.02 \\
(-1.37-1.32) \\
\mathbf{0 . 1 5}\end{array}$ & 0.68 & -0.04 & 0.970 \\
\hline Total PSED score & $\begin{array}{c}(-0.01-0.32) \\
\text { Table 4. Socioemotional Development (PSED Domain) with Mother } \\
\text { Child Interaction (OMCI total Score). Correlation between Mother- } \\
\text { Child Interaction (Mother-Child Total Score) and Socio-Emotional } \\
\text { Development (PSED) }\end{array}$ \\
\hline
\end{tabular}

The child score having mean (SD) i.e., $13.19( \pm 3.84)$ with minimum obtained score was 1 and maximum score was 21 . And the total mother-child score having mean (SD) i.e., 18.03
$( \pm 6.70)$ with minimum obtained score was 1 and maximum score was 36 .

Table 3. shows responses on basis of Profile of Socio Emotional development (PSED) tool score. Socio-emotional development four domain i.e., (social competence, emotional competence, self-regulation, executive functioning) were scored with the above-mentioned tools; total 160 study participants were eligible for PSED tool, social competence having mean $(S D)$ i.e., $5.84( \pm 3.23)$ with minimum obtained score was 0 and maximum score was 15 . Emotional competence having mean (SD) i.e., $3.16( \pm 1.77)$ with minimum obtained score was 0 and maximum score was 8 . Selfregulation having mean (SD) i.e., $7.81( \pm 3.44)$ with minimum obtained score was 1 and maximum score was 15 . Executive functioning having mean (SD) i.e., $1.51( \pm 1.04)$ with minimum obtained score was 0 and maximum score was 4 .

\section{DISCUSSION}

The present study was conducted to find out association between mother and child interaction and socio-emotional development of the children (0 - 36 months). The study population was from the rural area of Wardha district of Maharashtra with the sample size of 160 . The OMCI tool was used to assess the mother and child interaction and the PSED tool was used to assess the social and emotional developmental ability of the children. The study assessed the mother and child interaction and socio- emotional development of children from 0 - 36 months of age. Assessment of mother-child interaction and socio emotional development was done using OMCI and PSED tool. Present study found that OMCI scores were normally distributed, mother score having mean (SD) i.e., 22.99 ( \pm 5.38) with minimum obtained score was 13 and maximum score was 36 . The child score having mean (SD) i.e., $13.19( \pm 3.84)$ with minimum obtained score was 1 and maximum score was 21 . And the total mother-child score having mean (SD) i.e., 18.03 $( \pm 6.70)$ with minimum obtained score was 1 and maximum score was 36. The descriptive statistics of items on the OMCI with positive affect had the mean (SD) $2.30( \pm 0.62)$, and negative affect $2.48( \pm 0.78)$ and negative touch $2.71( \pm 0.58)$ was the mean score. Similarly, the mean score obtained for socio-emotional development in four domains i.e., (social competence, emotional competence, self-regulation and executive functioning). Social competence having mean (SD) i.e., $5.84( \pm 3.23)$ with minimum obtained score was 0 and maximum score was 15 . Emotional competence having mean (SD) i.e., $3.16( \pm 1.77)$ with minimum obtained score was 0 and maximum score was 8. Self-regulation having mean (SD) i.e., $7.81( \pm 3.44)$ with minimum obtained score was 1 and maximum score was 15 . Executive functioning having mean (SD) i.e., $1.51( \pm 1.04)$ with minimum obtained score was 0 and maximum score was 4 . And the total PSED score having mean (SD) i.e., $15.63( \pm 6.15)$ with minimum obtained score was 3 and maximum score was 31.A similar study by Yousafzai et al. ${ }^{11}$ found, compared to the OMCI scores, the production and reliability of an analytical instrument for assessing motherchild interactions in field studies was normally distributed. Mother score mean was 21.5 [SD 6.0], child score mean was 10.8 (SD 5.0) and mother-child total score was 32.3 (SD 10.0). 
The descriptive stats of OMCI items. The highest mean was positive effect $(2.38,0.87)$, and the lowest mean was negative effect $(0.02,0.22)$ and negative contact $(0.02,0.18)$. Internal performance for OMCI was strong with a total score alpha of 0.886 , mother score 0.829 and child score 0.780 . Our results found the similar findings like the baseline results of that study. Association of mother-child interaction and socioemotional development shows no significant association. For assessing the mother-child interaction, the OMCI tool was used, the tool comprises of different questions which allow to assess the mother score, child score and mother-child score. And for assessing the socio emotional development, the PSED tools was used, the tool comprises of different questions which allow to assess the child's social competence, emotional competence, self-regulation and executive functioning. The results for the association of both mother-child interaction and socio emotional development of child were analysed by unpaired t-test value, hence in this study no statistically significant association was found. Other studies revealed that gender and geographical location may become a factor in children's parental play in some countries. It may have been attributed to cultural differences. A Bangladesh study reveals that more parents routinely play with male children between the ages of 1 and 3, compared to female children of the same age. But in their rural areas, though 9 percent of mothers play with girls on a regular basis, the figure is 10 percent for boys. The difference in urban areas is bigger ( 9 percent versus 16 percent).

\section{CONCLUSIONS}

It is evident from this study that there is no statistically significant finding in mother-child interaction with socio emotional development i.e., coefficient 0.15 . However, positive correlation was found between OMCI score and PSED score. $\mathrm{R}$ $=0.3216^{*}$. Significant responsive care ratings were related to better socio-emotional outcomes; and responsive care was found to be statistically relevant, with higher maternal education rates, and there was positive association between socioeconomic status and socio emotional development (PSED score) (statistically significant) and it can be concluded that maximum socio emotional development was found in Class IV socio economic status. It can be further stated that inclusion of responsive care in child health interventions in the villages of Seloo (Wardha district), could have a valuable impact on child socio-emotional development. The OMCI may be useful in recognising important ways of improving responsive care behaviour, which may serve better purposes for potential intervention that improve children's growth through responsive care.

\section{Strengths and Limitations}

This study has many strengths. It is a low-cost method to assess sensitive treatment that does not rely on maternal selfreporting. Requires substantial technical and infrastructural resources, and to investigate the impact of treatment on the outcome of children in an undeserved group, a subset of data was collected, and profile for socio-emotional development tool (PSED) provides an early moment investment for every childhood development. This tool paves a way for reducing deprivation during early childhood development phase and is designed in a family-friendly protocol. Also creating limitations for this analysis are some of the strengths offered by the OMCI and PSED. It is also restrictive in higher level of observer bias. ${ }^{11}$

Data sharing statement provided by the authors is available with the full text of this article at jemds.com.

Financial or other competing interests: None.

Disclosure forms provided by the authors are available with the full text of this article at jemds.com.

\section{REFERENCES}

[1] Cerezo MA, Pons-Salvador G, Trenado RM. Mother-infant interaction and children's socio-emotional development with high-and low-risk mothers. Infant Behav Dev 2008;31(4):578-89.

[2] Brown JE, Isaacs J, Krinke B, et al. Nutrition through the life cycle. $5^{\text {th }}$ edn. Cengage Learning 2013.

[3] Social-Emotional Development Domain. Child Development (CA Dept of Education). [cited 2018 Jul 30]. https://www.cde.ca.gov/sp/cd/re/itf09socemodev.asp.

[4] What is Social \& Emotional Development. Child Mental Health? [cited 2018 Jan 15]. https:// dmh.mo.gov/healthykids/parents/social-emotionaldevelopment.html. socio-emotional development NCCP.pdf.

[5] Bornstein MH, Tamis-LeMonda CS. Maternal responsiveness and cognitive development in children. In: Bornstein MH, ed. New directions for child development. No. 43. The Jossey-Bass social and behavioral sciences series. Maternal responsiveness: characteristics and consequences. 1989:46-61.

[6] De Falco S, Emer A, Martini L, et al. Predictors of motherchild interaction quality and child attachment security in at-risk families. Front Psychol 2014;5:898.

[7] Lyon-Ruth K, Easterbrooks LA, Cibelli CD. Infant attachment strategies, infant mental lag and maternal depressive symptoms: predictors of internalizing and externalizing problems at age 7. Dev Psychol 1997;33(4):681-92.

[8] Feinberg ME, Kan ML, Goslin MC. Enhancing coparenting, parenting and child self-regulation: effects of family foundations 1 year after birth. Prev Sci 2009;10(3):27685.

[9] Rasheed M, Yousafzai AK. The development and reliability testing of an observation tool for assessing mother-child interaction in community-based field studies-experience from Pakistan. Conference paper accepted at the $16^{\text {th }}$ European Conference on Developmental Psychology, Lausanne, Switzerland, September 2013.

[10] Rasheed M, Yousafzai A. The development and reliability of an observational tool for assessing mother-child interactions in field studies-experience from Pakistan. Child Care Health Dev 2015;41(6):1161-71.

[11] Saleem HT, Surkan PJ. Parental pregnancy wantedness and child social-emotional development. Matern Child Health J 2014;18(4):930-8. 